\title{
What was supposed to be the role of a coordinator of oncological treatment, and what is it really like?
}

\author{
Karolina Osowiecka1, 2,3, Monika Rucińska ${ }^{4}$, Anna Andrzejczak³ ${ }^{3}$ Ewelina Żarłok $^{3}$, \\ Iwona Chrostek ${ }^{5}$, Sergiusz Nawrocki ${ }^{4}$
${ }^{1}$ Department of Psychology and Sociology of Health and Public Health, School of Public Health, University of Warmia and Mazury in Olsztyn, Poland
${ }^{2}$ Department of Public Health, Faculty of Health Sciences, Medical University of Warsaw, Poland ${ }^{3}$ Foundation Oncology 2025, Warsaw, Poland
${ }^{4}$ Department of Oncology, Faculty of Medicine, Collegium Medicum, University of Warmia and Mazury in Olsztyn, Poland \\ ${ }^{5}$ Ethics Clinical Research Center, Olsztyn, Poland
}

\begin{abstract}
Introduction. Due to the multidisciplinary nature of oncological treatment, it is necessary to coordinate it properly. In response to this need, an idea emerged to create a new profession in the system of oncological care, the so-called oncological treatment coordinator. The aim of the study was to assess the actual role of coordinators in hospitals in Poland. Material and methods. The study was carried out by means of a questionnaire among persons employed as coordinators and persons who act as coordinators within additional duties.

Results. The study involved 95 coordinators from various centers in Poland, half of which were recruited on purpose as coordinators. Less than half (40\%) have received training on their work. The main task of the coordinators is to ensure that the documentation related to the patient's Diagnostic and Oncological Treatment Card (DiLO) is complete, to set appointments for diagnostic tests and visits to doctors' offices and to cooperate with medical statistics departments. Only half of the coordinators inform or provide non-medical support to the patient. Coordinators face very different difficulties in their work.
\end{abstract}

Conclusions. Coordinators are a valuable professional group in the Polish oncological care system. However, there is a lack of clearly defined tasks, systematic training and support.

NOWOTWORY J Oncol 2020; 70, 1: 1-8

\section{Key words: coordinator, oncology package, cancer patient care system}

\section{Introduction}

Advances in technology and medicine have led in recent years to the introduction of various new methods, both diagnostic and therapeutic, for the diagnosis and treatment of cancer patients. Diagnostics and treatment of cancer have become more complex, require the participation of many specialists, and often require diagnostics and treatment in different sometimes distant - centers. This brings new challenges for oncological care, including the need for proper integration and coordination of diagnosis and treatment.
This problem was noticed many years ago. In oncological centers in Poland, attempts have been made to coordinate oncological activities in many ways, e.g. by arranging so-called "multidisciplinary meet-ups", creating organ clinics, assigning specialists to treat particular types of tumors. Thanks to the work of many specialists from the oncological community, a document entitled Strategia walkiz rakiem w Polsce 2015-2024 (Strategy for Combating Cancer in Poland 2015-2024) was created in 2014, which, among other things, included the idea of creating a new profession in the system of oncological 
care, the so-called coordinator of oncological treatment. The role of the coordinator of oncological treatment was to be a comprehensive and individual help for the patient to move efficiently in the health care system and quickly pass through the successive stages of oncological diagnosis and treatment. It is well known that a person who is suspected or has already been diagnosed with cancer faces various problems, not only of a medical nature, but also of an organizational, social, legal, psychological or spiritual character. Thus, a patient suffering from cancer requires not only efficient and timely diagnostics and prompt implementation of proper oncological treatment, but also care and support in non-medical areas at individual stages of diagnosis and treatment.

The coordinated model of oncological care was to create a new quality in the Polish healthcare system. The role of the coordinator of oncological treatment was to support a patient with cancer during diagnostics and oncological treatment, both in organizational terms and to provide them with help and support in the remaining areas of life, which are significantly affected by the suspicion and diagnosis of cancer. Therefore, such a person should not only have the skills and appropriate competence to organize oncological care, but should also have basic medical, legal, administrative, psychological and social knowledge and support skills in these areas. The persons acting as coordinators of oncological treatment should therefore be covered by an appropriate training program developed by a team consisting of representatives of various disciplines: medical, social, legal and psychooncological ones. Such training was to take place at the faculties of public health at medical faculties of universities.

The Regulation of the Minister of Health of October 20, 2014 amending the Regulation on guaranteed services in the field of hospital treatment introduced the obligation to appoint a so-called Coordinator [...], whose tasks include in particular providing the patient with information about the organization of the treatment process and its coordination, including ensuring cooperation between entities within the framework of comprehensive patient care. However, the Regulation did not specify the specific tasks and competences assigned to the coordinating function. Other solutions introduced at the same time - in particular the rules of accounting and handling the Diagnostic and Oncological Treatment Card (DiLO) - required the providers to carry out a number of administrative activities, which the hospitals have just handed over to their coordinators. It seems that, as a result, the role of the majority of coordinators appointed to operate in hospitals in accordance with the Regulation has in practice been reduced to an informational and administrative role only.

The aim of the work was to assess what is the real role of persons called coordinators in hospitals in Poland, what their duties are, who they are by profession, where they get the knowledge needed to perform those duties and what difficulties they encounter while performing their work.

\section{Material and methods}

The study was conducted among persons employed as coordinators and persons who act as coordinators within additional duties while being employed in other positions. In the first stage of the study, a list of centers in Poland which have concluded an agreement for the provision of oncology package services was drawn up based on data from the National Health Fund (NFZ) and the Ministry of Health - Health Needs Maps. 361 hospitals were then contacted by phone and it was verified whether individual centers actually provided services as part of the oncology package and whether there were persons employed as coordinators. One hundred and nine centers were excluded due to the fact that the services of the oncology package are provided sporadically or not at all and there were no person acting as coordinator in these centers. In 117 centers the coordinators could not be contacted or did not agree to participate in the study. In the remaining 135 hospitals, the coordinators agreed to take part in the study, eventually 95 coordinators from 75 centers returned the completed questionnaire or participated in a telephone interview. Among the above 75 centers, there were 15 multi-profile centers (which provide services in oncological surgery, radiotherapy and systemic treatment) and 60 single or dual-profile centers where no radiotherapy was performed. Thirty-two respondents (34\%) are coordinators working in multi-profile oncology centers, 63 respondents (66\%) are coordinators from smaller centers. The first stage of the study, consisting in drawing up a list of centers, was carried out from May to June 2019, while the study was conducted from July to October 2019

The study was carried out by means of a questionnaire drawn up for the purpose of this study. The questionnaire was sent by e-mail directly to the coordinators who agreed to the participate in the study and sent back to the researcher or completed by the researcher during a telephone conversation with the coordinator. The study was voluntary and anonymous.

The analysis of the data was carried out using descriptive statistics and the chi2 test was used to compare proportions in subgroups. The statistical significance level of $p<0.05$ was assumed. The statistical analysis was carried out using STATISTICA software, version 13.3. The project was implemented and financed within the statutory activities of the Fundacja Onkologia 2025.

\section{Results}

The study covered all centers which provide services within the scope of oncology package in Poland. The participation in the study was approved by the persons acting as coordinators in 135 out of 361 centers identified as the oncology package implementers. Finally, 95 coordinators representing all voivodeships returned the questionnaires (Fig. 1.).

Half of the examined coordinators (49 persons, 52\%) were recruited on purpose as coordinators, the remaining 46 per- 


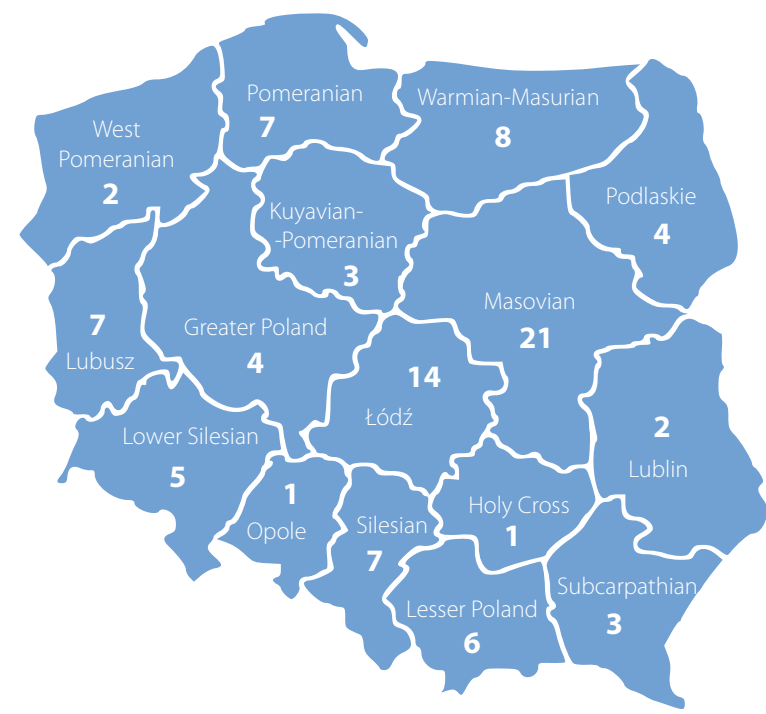

Figure 1. The number of coordinators who took part in the survey in particular voivodeships in Poland

sons (48\%) perform the coordinator's tasks as part of additional duties, working in other jobs. This group consists mainly of nurses (18 persons, 39\%), administrative staff (16 persons, 35\%) and medical secretaries/medical admissions clerk (11 persons, 24\%). In one case, it was a physician (Fig. 2.).

In multi-profile centers, significantly more often than in single or dual-profile ones, persons were deliberately employed as coordinators (75\% vs. $40 \%$; $p=0.001$ ).

Less than half of the coordinators surveyed (38 persons, 40\%) have received any training concerning their work: $23 \%$ of all the coordinators have either received training conducted by the NFZ (National Health Fund) or received professional assistance from the NFZ employee, 29 people (31\%) have taken part in internal/on-the-job training organized by the employer. Almost half of the coordinators (49\%) stated that they gained knowledge on their own on a trial-and-error basis, 41 people (43\%) declared that they gained knowledge mainly from the exchange of experience with coordinators of other centers, or from physicians who took part in case consultations in various hospitals and therefore had more experience and

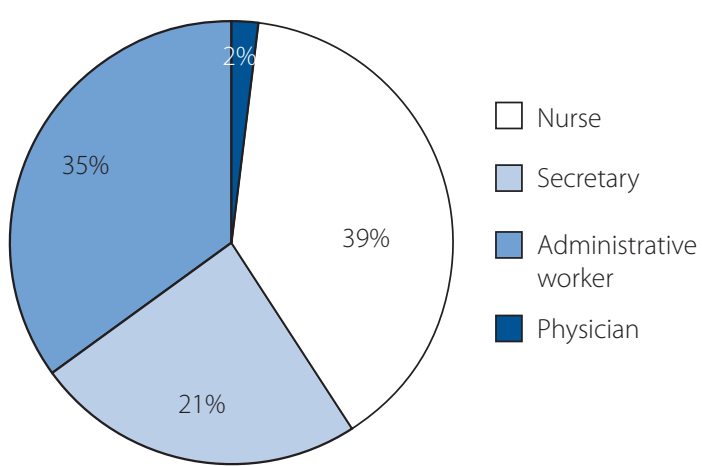

Figure 2. Persons performing the tasks of coordinator within additional duties, employed in other positions knowledge. The coordinators surveyed assessed that drawing on the experience of others was for them the most valuable form of gaining knowledge about how to perform the function of coordinator (Fig. 3.).

It turned out that individual coordinators carried out similar activities as part of their duties. Their main task is to ensure that the documentation related to the DiLO card is complete, e.g. they record in the medical records the case consultation and its decisions, they set appointments for diagnostic tests and visits to doctors' offices, they cooperate with medical statistics departments in order to properly account for oncological services (Fig. 4.).

These tasks did not differ depending on the type of center (multi-profile centers vs. single or dual-profile ones), except for the coordinator's participation in case consultations. Indeed, more often than not, coordinators were present at case consultations in multi-profile centers ( $p=0.03$ ) (Tab. I).

Almost all coordinators (97\%) have contact with patients. Most often this contact includes informing patients in person or by phone about fixed dates of diagnostic tests, dates of doctors' visits, a date commencing the treatment (81\%) and providing practical advice on tests/treatment (71\%). Only half of the coordinators (51\%) provide patients with information about the possibility of obtaining non-medical support, e.g. from a social worker, the same number (51\% of respondents) provide any non-medical support on their own (Fig. 5.).

There were no significant differences in the frequency and type of contact between the coordinator and the patients depending on the type of center (multi-profile centers vs. single or dual-profile ones).

A coordinator devotes 2 to 51 hours per week (on average $26.4 \pm 13.9$ hours, median 36 hours) to work. In the surveyed centers, a case consultation takes place at a frequency from 1 to 2 weeks to 6 times a week (average 2 times a week, median once a week). The duration of one case consultation depends on the number of patients and lasts from 0.5 to 7 hours (average $2.4 \pm 1.4$ hours, median 2 hours).

Only one third of the respondents (34\%) receive an additional remuneration for performing the duties of a coordinator, e.g. in the form of a bonus, of which 12 people (24.5\%) employed as a coordinator and 20 people (43.5\%) perform the duties of a coordinator within additional duties.

Coordinators face very different difficulties in their work. A quarter of the respondents indicated difficulties in cooperation with medical personnel, i.e. "indifference" of other employees, low interest of physicians in the subject of DiLO card, lack of respect for DiLO rules by physicians. Fourteen percent of persons indicated problems at the primary care level, such as incorrect issuing of DiLO cards, incorrect informing patients about the purpose of issuing the DiLO card, wrongly informing patients about centers that have a contract to provide services as part of an oncology package or a refusal to issue the DiLO card. The problem at the level of cooperation between 


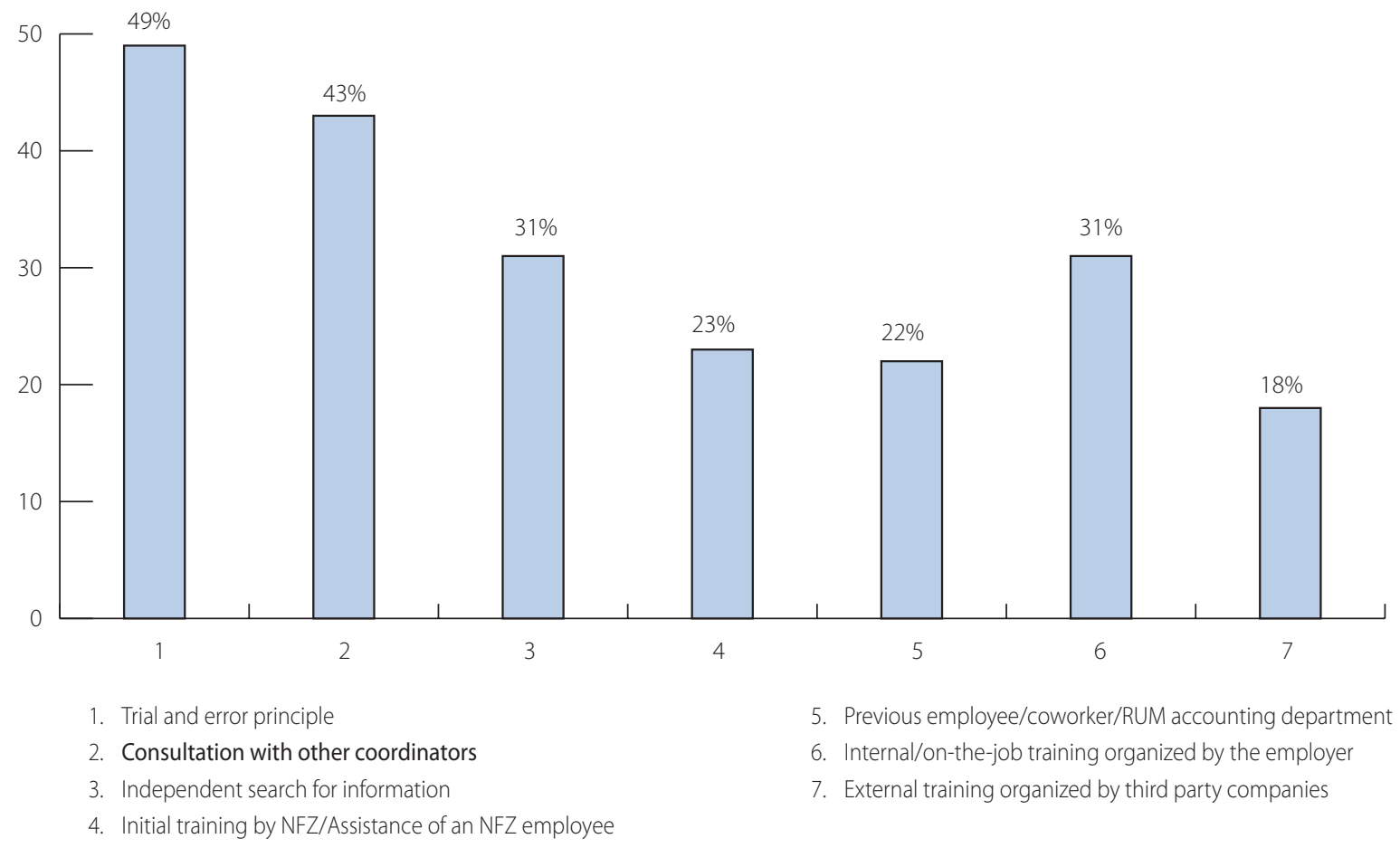

Figure 3. Sources of coordinators' knowledge

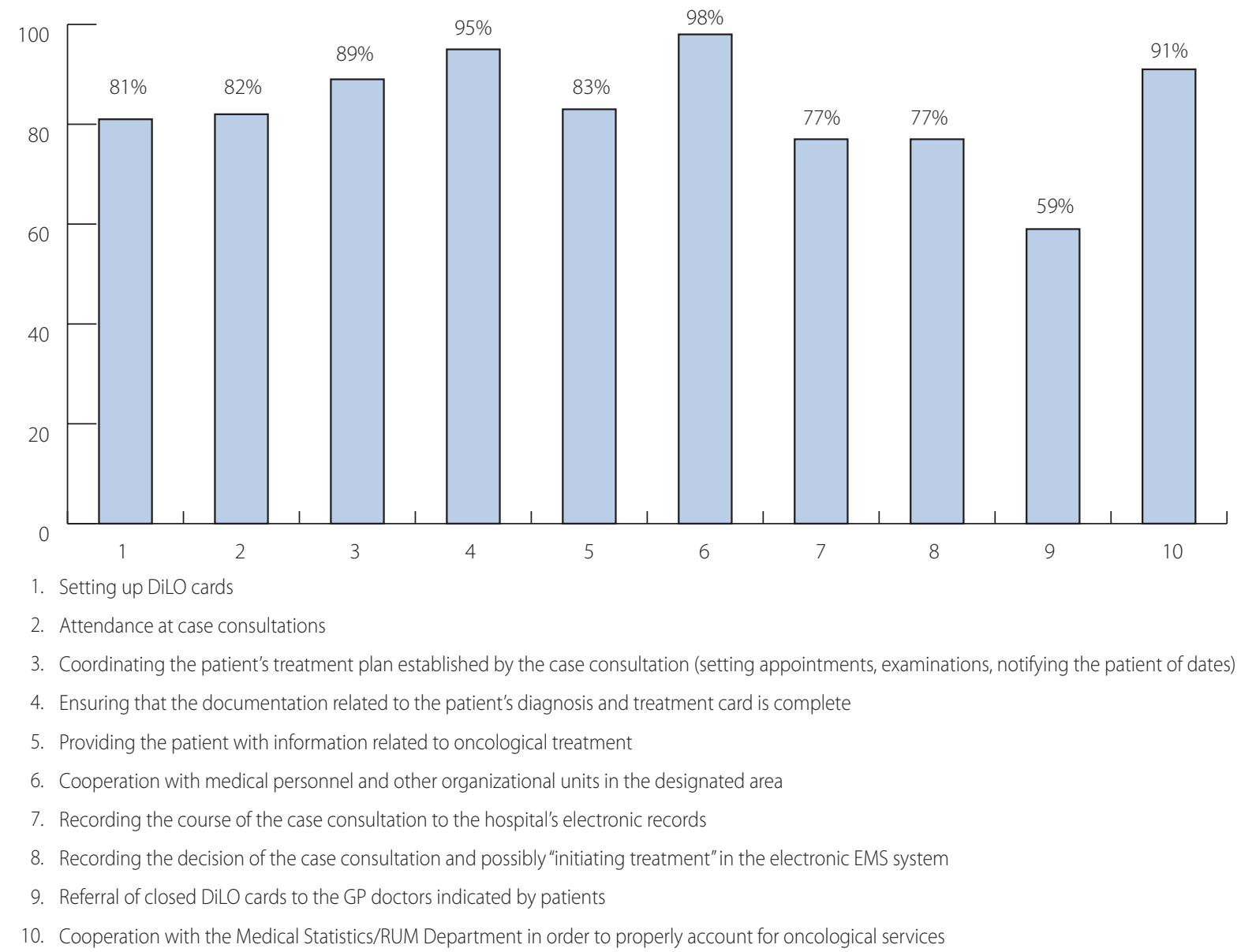

Figure 4. Scope of activities performed by the coordinators 
Table I. Tasks performed by the coordinators

\begin{tabular}{|c|c|c|c|}
\hline \multicolumn{4}{|c|}{ CENTER } \\
\hline & Multi-profile & Single or dual-profile & p \\
\hline & $33.7 \%$ & $66.3 \%$ & \\
\hline \multicolumn{4}{|c|}{ Setting up DiLO cards } \\
\hline no & $21.9 \%$ & $17.5 \%$ & \multirow[t]{2}{*}{0.60} \\
\hline yes & $78.1 \%$ & $82.5 \%$ & \\
\hline \multicolumn{4}{|c|}{ Participating in case consultations } \\
\hline no & $6.3 \%$ & $23.8 \%$ & \multirow[t]{2}{*}{0.03} \\
\hline yes & $93.8 \%$ & $76.2 \%$ & \\
\hline \multicolumn{4}{|c|}{ Coordinating the patient's treatment plan established by the case consultation } \\
\hline no & $9.4 \%$ & $11.1 \%$ & \multirow[t]{2}{*}{0.79} \\
\hline yes & $90.6 \%$ & $88.9 \%$ & \\
\hline \multicolumn{4}{|c|}{ Ensuring that the documentation related to the patient's diagnosis and treatment card is complete } \\
\hline no & $6.3 \%$ & $6.3 \%$ & \multirow[t]{2}{*}{0.99} \\
\hline yes & $93.8 \%$ & $93.7 \%$ & \\
\hline \multicolumn{4}{|c|}{ Providing the patient with information related to oncological treatment } \\
\hline no & $15.6 \%$ & $19.0 \%$ & \multirow[t]{2}{*}{0.68} \\
\hline yes & $84.4 \%$ & $81.0 \%$ & \\
\hline \multicolumn{4}{|c|}{ Cooperation with medical personnel and other organizational units in the designated area } \\
\hline no & $0.0 \%$ & $4.8 \%$ & \multirow[t]{2}{*}{0.21} \\
\hline yes & $100.0 \%$ & $95.2 \%$ & \\
\hline \multicolumn{4}{|c|}{ Recording the course of the case consultation to the hospital's electronic records } \\
\hline no & $12.5 \%$ & $28.6 \%$ & \multirow[t]{2}{*}{0.08} \\
\hline yes & $87.5 \%$ & $71.4 \%$ & \\
\hline \multicolumn{4}{|c|}{ Recording the decision of the case consultation meeting and possibly "initiating treatment" in the electronic EMS system } \\
\hline no & $18.8 \%$ & $27.0 \%$ & \multirow[t]{2}{*}{0.38} \\
\hline yes & $81.2 \%$ & $73.0 \%$ & \\
\hline \multicolumn{4}{|c|}{ Referral of closed DiLO cards to the GP doctors indicated by patients } \\
\hline no & $43.8 \%$ & $39.7 \%$ & \multirow[t]{2}{*}{0.70} \\
\hline yes & $56.2 \%$ & $60.3 \%$ & \\
\hline \multicolumn{4}{|c|}{ Cooperation with the Medical Statistics/RUM Department in order to properly account for oncological services } \\
\hline no & $12.5 \%$ & $9.5 \%$ & \multirow[t]{2}{*}{0.66} \\
\hline yes & $87.5 \%$ & $90.5 \%$ & \\
\hline
\end{tabular}

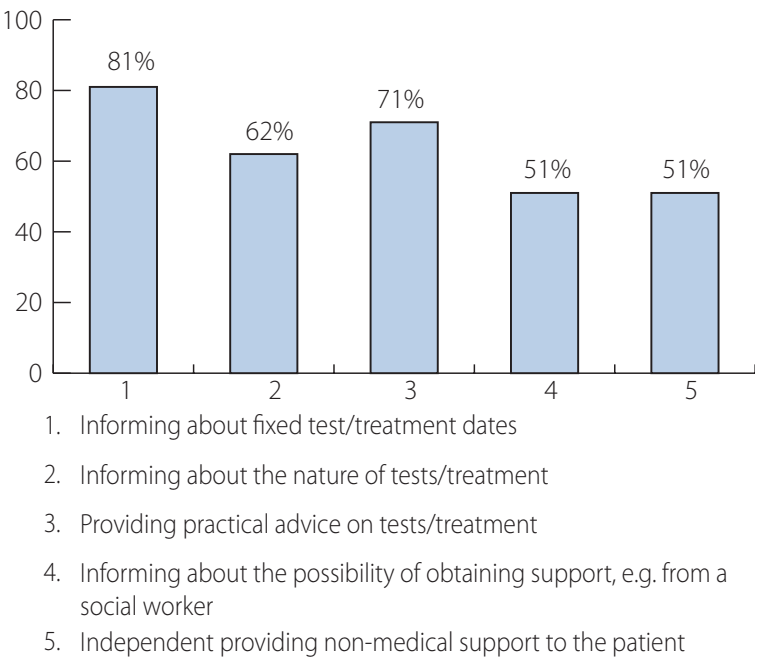

Figure 5. The role of coordinators as regards contacts with patients different oncology centers was indicated by 25 persons (26\%). This problem included locking individual stages, reluctance to change the stages of DiLO cards, extending the duration of individual stages, refusal to close an incorrectly issued card. The respondents pointed to problems with meeting the prescribed test dates in the oncology package by diagnostic laboratories. One third of the respondents pointed out the difficulties of coordination due to e.g. lack of possibility to view cards issued in other centers, lack of "centralized" collection/registration of issued DiLO cards. More than one third of the respondents (37\%) indicated a lack of flexibility of AP-DiLO application and various system limitations. Moreover, it turned out that in Poland there are significant differences in the interpretation of the rules of proper handling of the oncology package by both individual oncological centers and NFZ Departments. 


\section{Discussion}

A patient using a complex system of diagnostics and oncological care requires appropriate guidance and support. This system covers different elements of healthcare, such as: GP, diagnostic laboratories, various outpatient and oncological wards, centers providing rehabilitation, palliative care and psychooncological support. The task of individual components of this system is efficient diagnostics and quick undertaking of appropriate therapeutic actions, which will result in curing the patient and improve/maintain a patient's quality of life. It is also important to reduce costs, make good use of local (basic) healthcare resources and relieve the burden on specialists in oncology centers.

Programs to "coordinate" the diagnosis and treatment of cancer patients have already been introduced in various countries. The first such coordination program was designed in 1990 by Harold P. Freeman at Harlem Hospital in New York. The program was addressed to the group of African-Americans, because in this group of patients, according to the analysis, cancer was detected at a more advanced stage (only $6 \%$ of patients were at the 1st stage), which resulted in high mortality (5-year survival was estimated at 39\%) [1]. It has been noted that women who were found to have a suspicious change in their breasts in the screening test, and who were "coordinated", were more often and more likely to have a breast tumor biopsy compared to 'uncoordinated' women (respectively: $87.5 \%$ vs. 56.6\%) [1]. The next steps were to coordinate the process of diagnosis and treatment of women undergoing screening mammography. The study involved 325 women who were suspected on the basis of mammography and subsequently diagnosed with breast cancer - the 5-year total survival in this group increased to $70 \%$ compared to the 5 -year survival rate of $39 \%$ before the introduction of the above intervention [2]. Also, in the USA, a project was introduced which aimed to improve the treatment results of patients with a low level of education, low income, without social support by eliminating obstacles to rapid diagnosis and treatment of cancer, shortening the time of waiting for diagnosis and therapy $[3,4]$. A key figure in this program was the coordinator, whose role was to coordinate visits to doctors' surgeries, hospitals, clinics, contacting the insurer and patient support organizations, emotional support for patients, contacting their family doctor, ensuring the availability of relevant medical records at scheduled visits, providing access to clinical trials, facilitating access to financial support and assisting with formal matters, organizing transport and/ or care for a child or elderly family member, and organizing interpreter services, as well as monitoring patient satisfaction with the oncology care system. Thanks to this program, including the work of the coordinators, the screening efficiency of mammography has been improved, the degree of cancer severity at the time of detection has been slightly reduced, times of waiting for diagnosis and treatment have been shortened, the access to healthcare has been improved, the cost effectiveness has been reduced and patient satisfaction has improved. Harold P. Freeman and Rian L. Rodriguez [4], drawing on 20 years of experience, have created the general principles for the proper functioning of the oncological care coordination model. The basic principle of this model is a patient's smooth and timely passage through the various stages of diagnosis and treatment, including rehabilitation and control tests.

In Poland, the coordination of the "patient pathway" in the system is formally established only from the moment of the case consultation to the end of treatment. In principle, coordinators do not take part in the earlier stages of diagnosis (screening, cancer suspicion, initial and in-depth diagnostics). The lack of effectiveness of our patient coordination system may result from the lack of patient support at the beginning of the path to cancer diagnosis, at the time of suspected cancer and at the first stage of diagnosis (to obtain a histopathological diagnosis). The coordinators also do not participate in the stage of broadly understood patient rehabilitation (physical, social, professional) and in the organization of follow-up examinations after the end of treatment (both after the treatment of the patient and in case of progression/recovery of the disease).

The second principle of proper functioning of the oncological care coordination model is to eliminate accessibility barriers to all stages that a patient goes through in the healthcare system. This is possible with properly planned/organized activities of diagnostic and treatment centers and individual patient coordination.

The third principle for the proper functioning of the oncological care coordination model is to clearly define the responsibilities, role and responsibilities of the coordinator. It is emphasized that the role of a coordinator is sometimes naturally performed by oncological nurses who, due to their function, are in close relationship with the patient and often provide not only medical and nursing support, but also psychological, dietary, informational, social and legal one [5-9].

The oncology package, introduced in Poland in 2015, includes the DiLO card as a tool to manage a rapid oncology therapy package and oncology care coordinators whose function has not been precisely defined. According to the National Health Fund, the coordinator supervises the process of treatment of a patient from the moment of referral to a case consultation until the end of treatment, supports the patients in terms of information, administration and organization, and helps them to communicate with physicians. After completing the oncological treatment and closing the DiLO card, the patient goes under the care of a primary care physician (GP). According to the NFZ [10], the tasks of a coordinator include: attendance at case meetings, coordinating the patient's treatment plan established by the case meeting, ensuring that the documentation related to the DiLO card is complete, providing the patient with information related to oncological treatment, cooperation with medical personnel and other organizational units in the designated area introducing the conciliation in the 
hospital system, supplementing the case consultation decision on further treatment in the DiLO system, sending closed DiLO cards back to GPs. The provider is obliged to comply with the conditions imposed by the NFZ and usually only fulfils the recommendations to which it is obliged. Any additional activities that would be beneficial to the patient, but are not required by the payer, do not have to and are not performed by providers mainly due to additional costs. Despite the lack of guidelines for the implementation of support for non-medical needs of the patient, in our study, some coordinators show empathy for patients and half of them provide, for example, information about the possibility of receiving non-medical support from, among others, a psychologist, a social worker, and even provide such assistance themselves. At the same time, the problems faced by the coordinators are generated more by the system itself than the organizational, clinical and social challenges associated with cancer. Excessive administrative work, resulting from the negligence of the system, takes time and creates understandable frustration - coordinators would prefer to devote this time to patients.

Another issue identified by Freeman is the need for training and acquisition of skills necessary for the work of the coordinator. In Poland, there is no structural support for coordinators in the area of knowledge, competence improvement, tools, basic assistance in solving current problems. The results of the survey show that the coordinators most often learn by exchanging experience with other coordinators or try to solve problems on a trial and error basis. The authors of various papers stress the importance of the level of skills, knowledge and experience of persons acting as oncological treatment coordinators and point out that such duties should not be fulfilled by persons without appropriate qualifications [5, 9]. The Minister of Health in the National Oncological Strategy declares the development of a post-graduate education program for the coordinator of oncological care. Oncological care coordinator is not a separate profession in Poland.

In view of the different tasks faced by coordinators, they should have particular aptitudes, knowledge and skills. According to our survey, half of the coordinators were deliberately hired for the position of coordinator, but there are no specific criteria for selecting such people for the above position, the requirements they should meet (profession, education, skills), and there is no proper training of candidates for coordinators. Nearly $40 \%$ of the persons who perform the coordinator's tasks within additional duties are employed as nurses, who have to organize the work themselves and often do not have enough time for patients. A majority of persons who have been assigned a coordinating role as additional work are administrative staff or medical secretaries. It can be assumed that the large number of administrative and accounting duties related to the oncology package induces hospitals to entrust the function of coordinator to persons experienced in administrative work rather than in contact with the patient.
Another principle of proper functioning of the oncological care coordination model is to define the points from which the patient coordination process will start and end. It should be remembered that the path of a cancer patient does not end with the completion of basic oncological treatment; patients require rehabilitation, follow-up and diagnostic tests, often the implementation of oncological re-treatment due to progression or relapse of the disease or palliative care. It is emphasized that comprehensiveness, integration of the treatment plan is an important factor which increases the availability of various methods of treatment and thus affects the survival of patients [11]. Good coordination reduces stress, fatigue and improves the quality of patients'life [12, 13]. Swanson [14] demonstrated a significantly statistical decrease in stress levels among cancer patients receiving support from the coordinating nurse. A randomized, controlled study by Kevin Fiscell [15] showed that the introduction of a coordination program has improved healthcare satisfaction in patients with breast and colorectal cancer. Similarly, in a study by Carroll [16], it turned out that patients who were properly coordinated received adequate psychological support, assistance in information needs and problem solving.

In Canada, a program of coordination in oncological care between family doctors and specialists has been introduced at both the systemic and individual levels. Effective and timely transfer of medical information about a patient between medical care units as well as clearly defined roles for each provider are essential for good oncological care coordination. Despite technological progress, there are still communication challenges that may lead to serious consequences for clinical decision making [17]. A meta-analysis conducted in the USA showed that the coordination of oncological care improves the process of diagnosis, treatment and terminal care of patients [18].

However, there is still a lack of appropriate tools to test and validate the effectiveness of the patient coordination program [5]. Similarly, in Poland, we do not have any system for evaluating the changes introduced in the system, nor do we have tools to check the level of patients' satisfaction with the quality of oncological coordination.

\section{Conclusions}

The coordinators in the Polish system of oncological care are a new, undoubtedly extremely valuable and with great potential, professional group. However, there is a lack of clearly defined tasks to be undertaken. In addition, oncology coordinators do not receive systematic training, they lack support.

Conflict of interest: none declared

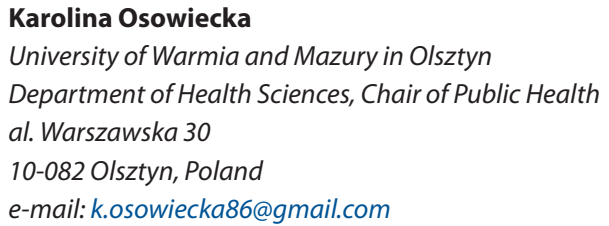


Received: 10 Dec 2019

Accepted: 4 Feb 2020

\section{References}

1. Freeman HP, Muth BJ, Kerner JF. Expanding access to cancer screening and clinical follow-up among the medically underserved. Cancer Pract. 1995; 3(1): 19-30, indexed in Pubmed: 7704057.

2. Oluwole SF, Ali AO, Adu A, et al. Impact of a cancer screening program on breast cancer stage at diagnosis in a medically underserved urban community. J Am Coll Surg. 2003; 196(2): 180-188, doi: 10.1016/S10727515(02)01765-9, indexed in Pubmed: 12595043.

3. A summary of the American Cancer Society Report to the Nation: cancer in the poor. CA Cancer J Clin. 1989; 39(5): 263-265, doi: 10.3322/ canjclin.39.5.263, indexed in Pubmed: 2513098.

4. Freeman HP, Rodriguez RL. History and principles of patient navigation. Cancer. 2011; 117(15 Suppl): 3539-3542, doi: 10.1002/cncr.26262, indexed in Pubmed: 21780088.

5. Shejila $\mathrm{CH}$, Pai MS, Fernandes DJ. Oncology Nurse Navigator Programme A narrative review. 2015; 5: 2249-7110.

6. Seek A, Hogle WP. Modeling a better way: navigating the healthcare system for patients with lung cancer. Clin J Oncol Nurs. 2007; 11(1): 81-85, doi: 10.1188/07.CJON.81-85, indexed in Pubmed: 17441399.

7. Curran CR. Navigation the chaotic health care system. Nurs Econ. 2003; 21: 261.

8. Fischer SM, Sauaia A, Kutner JS. Patient navigation: a culturally competent strategy to address disparities in palliative care. J Palliat Med. 2007; 10(5): 1023-1028, doi: 10.1089/jpm.2007.0070, indexed in Pubmed: 17985954.

9. Monas L, Toren O, Uziely B, et al. The oncology nurse coordinator: role perceptions of staff members and nurse coordinators. Isr J Health Policy Res. 2017; 6(1): 66, doi: 10.1186/s13584-017-0186-8, indexed in Pubmed: 29191228.
10. Pakiet onkologiczny. https://www.nfz.gov.pl/dla-swiadczeniodawcy/ pakiet-onkologiczny/.

11. Reyna C, Lee MC. Breast cancer in young women: special considerations in multidisciplinary care. J Multidiscip Healthc. 2014; 7: 419-429, doi: 10.2147/JMDH.S49994, indexed in Pubmed: 25300196.

12. Skrutkowski $M$, Saucier $A$, Eades $M$, et al. Impact of a pivot nurse in oncology on patients with lung or breast cancer: symptom distress, fatigue, quality of life, and use of healthcare resources. Oncol Nurs Forum. 2008; 35(6): 948-954, doi: 10.1188/08.ONF.948-954, indexed in Pubmed: 18980926.

13. Robinson-White $\mathrm{S}$, Conroy $\mathrm{B}$, Slavish $\mathrm{KH}$, et al. Patient navigation in breast cancer: a systematic review. Cancer Nurs. 2010; 33(2): 127-140, doi: 10.1097/NCC.0b013e3181c40401, indexed in Pubmed: 20142736.

14. Swanson J, Koch L. The role of the oncology nurse navigator in distress management of adult inpatients with cancer: a retrospective study. Oncol Nurs Forum. 2010; 37(1): 69-76, doi: 10.1188/10.ONF.69-76, indexed in Pubmed: 20044341.

15. Fiscella K, Whitley $E$, Hendren $\mathrm{S}$, et al. Patient navigation for breast and colorectal cancer treatment: a randomized trial. Cancer Epidemiol Biomarkers Prev. 2012; 21(10): 1673-1681, doi: 10.1158/1055-9965. EPI-12-0506, indexed in Pubmed: 23045542.

16. Carroll JK, Humiston SG, Meldrum SC, et al. Patients' experiences with navigation for cancer care. Patient Educ Couns. 2010; 80(2): 241-247, doi: 10.1016/j.pec.2009.10.024, indexed in Pubmed: 20006459.

17. Easley J, Miedema B, Carroll JC, et al. Coordination of cancer care between family physicians and cancer specialists: Importance of communication. Can Fam Physician. 2016; 62(10): e608-e615, indexed in Pubmed: 27737996.

18. Gorin SS, Haggstrom D, Han PKJ, et al. Cancer Care Coordination: a Systematic Review and Meta-Analysis of Over 30 Years of Empirical Studies. Ann Behav Med. 2017; 51(4): 532-546, doi: 10.1007/s12160017-9876-2, indexed in Pubmed: 28685390.

\section{From the Editorial Office}

The paper raises an issue important for the healthcare system in Poland. However, it is the duty of the Editorial Office to draw attention to significant reservations concerning chiefly the methodology of the conducted research, which - independently of each other - were pointed out by both reviewers. However, the Editorial Office recognizes the importance of the problem for the organization of oncological care in our country and despite the reservations of the reviewers (largely explained by the Authors in the submitted amendments) decided to publish the paper in Nowotwory. Journal of Oncology.

The results of the study and data cited in the paper come from the report by Onkologia 2025 Foundation (January 2020) entitled Koordynatorzy. Kim sq i jakq funkcję pełniq koordynatorzy pacjenta onkologicznego? Wyniki badania ankietowego (Coordinators. Who are the coordinators of an oncological patient and what is their function? Results of the survey). 